\title{
Comparing the efficacy of therapeutic packages in Persian Medicine with Classical Medicine in overweight patients: a randomized clinical trial
}

Liely Hamidnia $^{1,2}$, Mohsen Nematy ${ }^{3,4}$, Roshanak Salari ${ }^{5}$, Ali Taghipour ${ }^{6,7}$, Malihe Motavasselian $^{8}$

${ }^{1}$ Ph.D. Student of Persian Medicine, Department of Persian Medicine, School of Persian and Complementary Medicine, Mashhad University of Medical Sciences, Mashhad, Iran

${ }^{2}$ Student Research Committee, Mashhad University of Medical Sciences, Mashhad, Iran

${ }^{3}$ Ph.D. of Clinical Nutrition, Associate Professor, Department of Nutrition, School of Medicine, Mashhad University of Medical Sciences, Mashhad, Iran

${ }^{4}$ Ph.D. of Clinical Nutrition, Associate Professor, Metabolic Syndrome Research Center, Mashhad University of Medical Sciences, Mashhad, Iran

${ }^{5}$ Ph.D. of Drug control, Assistant Professor, Department of Clinical Persian Pharmacy, School of Persian and Complementary Medicine, Mashhad University of Medical Sciences. Mashhad, Iran

${ }^{6}$ Ph.D. of Epidemiology, Associate Professor, Department of Epidemiology \& Biostatistics, School of Health, Mashhad University of Medical Sciences, Mashhad, Iran

${ }^{7} \mathrm{Ph}$.D. of Epidemiology, Associate Professor, Social Determinants of Health Research Center, Mashhad University of Medical Sciences, Mashhad, Iran

${ }^{8}$ Ph.D. of Persian Medicine, Assistant Professor, Department of Persian Medicine, School of Persian and Complementary Medicine, Mashhad University of Medical Sciences, Mashhad, Iran

Type of article: Original

\begin{abstract}
Background: Obesity is a major risk factor for many diseases. In Persian Medicine, much emphasis has been put on the balanced weight that maintains health. Therefore, the treatment of obesity is a top priority for health care in Persian and Classical Medicine.

Objective: To compare the efficacy of therapeutic packages in Persian Medicine with Classical Medicine in overweight treatment.

Methods: This randomized clinical trial was conducted at Ghaem Hospital in Mashhad, Iran, from August 22, 2016 to December 20, 2016. Sixty-nine overweight women with body mass index (BMI) of 27-29.9 and waist circumference more than $88 \mathrm{~cm}$ based on inclusion and exclusion criteria, were included in the study. To control bias in sampling, with considering that the age variable is an interventional factor in the process of effective treatment, in addition to using the random allocation method, the population were studied in three groups of 18 30 years old, 31-50 years old and $>50$ years old, who were classified by blocking method, and three types of treatment interventions were performed in each age group: Group A (Classical diet and orlistat), Group B (Persian diet and MDB) and Group C (classical diet and MDB). Calorie consumption was equivalent in the three groups. Blinding was done only for patients. The treatment period was three months in all three groups. Subsequently, we analyzed the effectiveness of the therapeutic packages on anthropometric index, body composition and laboratory parameters in the three groups. The data were analyzed using SPSS version 16 . We used descriptive statistics, Kolmogorov-Smirnov, ANOVA, paired-samples t-test, non-parametric Wilcoxon test and regression methods for the analyses of primary and secondary outcomes.

Results: Although anthropometric index and fat mass decreased highly significantly in all three intervention groups $(\mathrm{p}<0.001)$, the B group led to a further decrease in BMI (Mean \pm SD: $1.61 \pm 1.03$ ), weight (Mean \pm SD:
\end{abstract}

\section{Corresponding author:}

Assistant Professor Dr. Malihe Motavasselian, Department of Persian Medicine, School of Persian and Complementary Medicine, Mashhad University of Medical Sciences, Mashhad, Iran.

Tel: +98.5138848930, Fax: +98.5138829279, Email: m_motevasselian@yahoo.com

Received: October 28, 2017, Accepted: Janaury 20, 2018, Published: June 2018

iThenticate screening: January 20, 2018, English editing: March 12, 2018, Quality control: April 05, 2018

Ethics approval: IR.MUMS.REC.1395.166

This article has been reviewed / commented by four experts

(C) 2018 The Authors. This is an open access article under the terms of the Creative Commons Attribution-NonCommercialNoDerivs License, which permits use and distribution in any medium, provided the original work is properly cited, the use is non-commercial and no modifications or adaptations are made. 
4.79 \pm 2.26 ), waist circumference (Mean \pm SD: $4.25 \pm 0.59$ ) and Fat mass (Mean \pm SD: $3.24 \pm 2.70$ ), compared with the other two groups. Lipid profile and FBS in groups B and C had significant decrease before and after the intervention, but Group A had no significant effect before or after the intervention. Other laboratory parameters did not change significantly before or after the treatment in the three groups.

Conclusion: In this study, Classical Medicine and Persian Medicine had the same levels of effectiveness but Persian Medicine brought a greater reduction in body weight, fat mass\%, lipid profile and fasting blood glucose than Classical Medicine during the study period. So Persian Medicine can be effective in weight loss as an alternative therapy, but more studies are needed.

Trial registration: The trial was registered at the Iranian Registry of Clinical Trials (http://www.irct.ir) with the Irct ID: (IRCT 2016041927477N1).

Funding: This paper is supported by a grant from the Research Council, Mashhad University of Medical Sciences, Mashhad, Iran.

Keywords: Obesity, Persian Medicine, Nigella sativa, Carum copticum, Zataria multiflora, Mastic gum

\section{Introduction}

Overweight and obesity are problems which have arisen over the past century. The prevalence of overweightness and obesity has increased over the past three decades, especially in developing countries (1). Overweightness occurs as a result of an imbalance between food consumed and physical activity (2). Obesity is a major risk factor for diabetes, cardiovascular disease, cancer, non-alcoholic fatty liver, osteoarthritis and other diseases (3). Human adipose tissue is an active endocrine organ that releases many inflammatory adipokines that increases obesity (4). Increasing fat tissue mass causes macrophage penetration and increased inflammation, and thus causes cellular changes in adipose tissue (5). The long-term therapeutic results of obesity are disappointing, and chemical drugs used for the treatment of obesity are associated with complications such as headache, nausea, heart attack, anxiety and depression. Orlistat is an anti-obesity drug that selectively and potentially inhibits the absorption and hydrolysis of lipids (6). Because of potential adverse side effects of anti-obesity agents, the popularity of complementary medicine has increased throughout the world. Numerous studies have discovered potential effects of herbal remedies for the treatment of obesity (7). The main mechanisms of natural products in the treatment of obesity are stimulated metabolism, suppressed appetite, affected serotonin levels or impairment of fat absorption (8). Obesity is a phlegmatic disease. Balgham is Barid Ratab (cold and wet) by temperament (9). Majoon Davaye Balgham (MDB) is an herbal formulation which contains Nigella sativa, Carum copticum, Zataria multiflora and Mastic gum on a honey base (10). The ingredients of this product which are based on the books of Makhzan-al-Advia and Al-Qanun fi al-Tibb (from the important sources of Persian Medicine) have hot and dry temperament that is effective in the treatment of phlegmatic diseases including obesity $(9,11)$. In various studies, anti-inflammatory and anti-oxidative effects (12-16) and lipid profile reducing effects $(14,17-19)$ of components of this herbal formulation have been proven. Considering the major role of oxidative stress in the pathophysiology of obesity, and the inverse relationship between indicators of antioxidant defense and body fat percentage and central obesity (20), MDB can be effective in the treatment of obesity. Also, recent studies have strongly emphasized the importance of a low-calorie diet in the treatment of obesity, and the relationship between excess energy consumption in the obesity process and inflammation has been approved (21). Therefore, reducing energy consumption and caloric restriction will reduce the inflammatory response in the body. Persian Medicine also adopted a special look at the individual's diet in the treatment of obesity. It is important to note that in the formulation of diet and medicine based on Persian Medicine, much emphasis has been placed on the consumption of plants and foods with hot and dry temperament in obesity treatment (9). Hot and dry plants cause weight loss through different mechanisms such as enhanced thermogenesis and activation of protein kinase, reduced expression of multiple genes involved in adipogenesis (22), and increasing energy consumption and oxidation of lipids and reduced appetite (23).

There is still a significant gap in the treatment of obesity and overweightness in children and adults in classical medicine (24). Considering the widespread pandemic of overweightness and obesity, developing more strategies for treating obesity is essential. In general, according to the results of previous studies, long-term therapeutic results of obesity are frustrating, and chemical drugs used to treat obesity have complications such as headache and nausea, heart attack, anxiety and depression $(25,26)$. On the other hand, medicines used in Classical Medicine for the treatment of obesity have short-term therapeutic effects and reversal of weight in short time after discontinuation of the drug (27). Bariatric surgery can be effective in weight loss, but there is the risk of complications, reoperation and death (28). So, there are many gaps in the treatment of obesity in Classical Medicine but traditional medicine has fewer side effects and greater acceptability in patients. Therefore, it was decided to conduct a more comprehensive study to obtain the synergistic effects of herbal formulation (MDB) and management of the patients' diet based on 
the recommendations of Persian Medicine (29). It is hoped that by considering the holistic view of Persian Medicine in the treatment of obesity and overweightness, a new horizon will be achieved in the treatment and prevention of obesity in the near future. The purpose of this study was to compare the efficacy of therapeutic package in Persian Medicine with Classical medicine in overweight treatment.

\section{Material and Methods}

\subsection{Trial design and participants}

This study was a randomized clinical trial that was conducted from August 22, 2016 to December 20, 2016. This clinical trial was conducted in an Iranian governmental educational hospital (Nutrition Clinic of Ghaem Hospital). The research population was comprised of overweight women [Body Mass Index (BMI): 27-29.9 kg/m²] with considering the inclusion and exclusion criteria in the study. Anthropometric index, body composition and laboratory parameters were analyzed for each patient. To control bias in sampling, with considering that the age variable as an interventional factor in the process of effective treatment, in addition to using the random allocation method, the population was studied in three groups of 18 to 30 years old, 31 to 50 years old and more than 50 years old, and were classified by blocking method, and three types of treatment interventions were performed in each age group.

\subsection{Selection criteria}

The inclusion criteria for participation in this study were: 1) overweight women aged 18-60, 2) BMI between 27 and $29.9 \mathrm{~kg} / \mathrm{m}^{2}$, waist circumference more than $88 \mathrm{~cm}$. Exclusion criteria included patients with diabetes, hypertension; chronic liver disease; chronic renal failure; heavy cigarette smoking (more than 20 cigarettes per day); obesity due to metabolic disorders; family history of obesity; pregnancy; lactation; AIDS; hepatitis; cancer; obese patients referred to obesity clinics in the past 6 months; patients with fat and body composition lower than muscle based on a body analyzer device; history of intolerance or allergy to honey, Nigella sativa, Carum copticum, Zataria multiflora or Mastic gum. Figure 1 shows the CONSORT flow diagram of the trial.

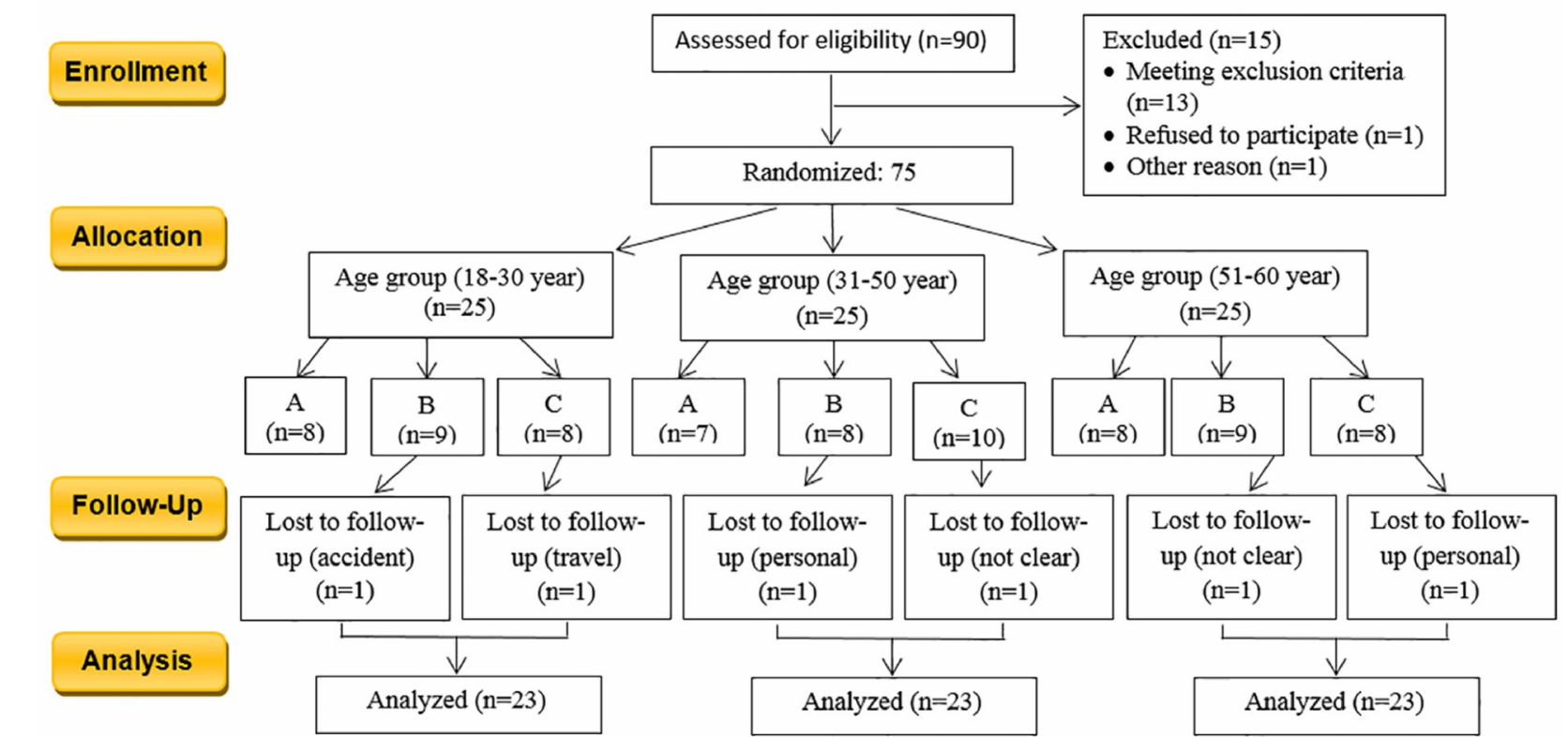

A: treated by conventional diet and orlistat, B: treated by Persian diet and herbal formulation (MDB); C: conventional diet and herbal formulation (MDB)

Figure 1. CONSORT diagram of the study

\subsection{Intervention}

This study was designed as a prospective, three-group randomized, single-blind study. In this clinical trial, 90 overweight women with (BMI: 27 to $29.9 \mathrm{~kg} / \mathrm{m}^{2}$ ) were visited at the hospital, and 21 Patients were excluded because they declined to participate or they met one or more of the exclusion criteria. Sixty-nine subjects were categorized with the method (random allocation) into three groups (18-30 years, 31-50 years, and >50 years) and then by blocking method, three types of treatment interventions were performed in each age group. The conventional 
medicine diet and orlistat was compared with a recommended diet of Persian Medicine and herbal formulation (MDB). The participants in this study were divided into three treatment groups A, B and C. Group A was treated by conventional diet and orlistat, Group B was treated by Persian diet and herbal formulation (MDB) and Group C was treated by conventional diet and herbal formulation (MDB). The conventional diet was recommended by dietitians on specific forms and the diet of Persian Medicine was accurately determined on the basis of Persian Traditional Medicine. It should be noted that the calorie diet was similar in the three groups, in which foods with hot and dry temperament recommended by Persian Medicine sources (39) were selected from the main and alternative lists of conventional diet, and foods with cold and wet temperament, the consumption of which was forbidden to obese people in the sources of Persian Medicine $(9,29)$ were removed from the main and alternative lists of conventional diet. Participants in this study were on a low-calorie diet designed to reduce the initial weight of 0.5 to $1 \mathrm{~kg} / \mathrm{week}$. The calorie distribution was as follows: $30 \%$ fat $(10 \%$ saturated, $10 \%$ monounsaturated and $10 \%$ polyunsaturated, up to $70 \mathrm{gr} /$ day), $50 \%$ carbohydrates and $20 \%$ protein (2). The caloric intake in this study was estimated at $40 \%$ to reduce caloric intake. Specific caloric intake was between 1,200 and 1,600 Kcal/day in women. Cap orlistat and MDB were prescribed respectively at $120 \mathrm{mg}$ and $5 \mathrm{gr} /$ twice a day. The treatment period lasted for 12 weeks in the three groups. Dietary recall forms were provided to patients to assess diet at home and to ensure medicine was taken by the patients, who were asked to return the medicine container in each visit. The container was weighed, and patients who did not consume more than $30 \%$ of the prescribed medication were excluded from the study. Demographics and medical records of the participants were collected by questionnaires. All participants underwent physical examination and anthropometric evaluation at the beginning of the treatment and at weeks 2, 4, 8, 10 and 12. Participants were monitored for possible changes in drug and possible side effects each visit. For all patients, height was measured using a wall stadiometer and weight (light clothing without shoes), body mass index and body composition were measured using a body analyzer device (Tanita model). Blood collections for serological data were conducted only at the first and last visit (week 12). The peripheral blood samples were obtained following 8 hours overnight fasting. All measurements were performed at the laboratory under the supervision of Mashhad University of Medical Sciences. Serological data including cholesterol (Chol), low density lipoprotein (LDL), high density lipoprotein (HDL), triglycerides (TG), fasting blood glucose (FBS), tests of renal function including blood urea and creatinine and liver function tests including aspartate transaminase (AST), alanine transaminase (ALT) and alkaline phosphatase tests (ALKP), thyroid hormones (T3.T4.TSH), Fe and $\mathrm{Zn}$ were investigated. All the measurements were carried out according to standardized established method, only at the first and the last visit (week 12).

\subsection{Formulation of herbal medicine}

Nigella sativa (Family Ranunculaceae), Trachyspermum ammi (Family Apiacea), Zataria multiflora (Family Lamiaceae), Mastic gum (Family anacardiaceae) and honey were purchased from a local market, and used after necessary investigations and observations were carried out by a botanical expert of Ferdowsi University of Mashhad, and the Herbarium code was received (Zataria multiflora: 10944, Trachyspermum ammi: 17155, nigella sativa: 17715). After removing the impurities, the drug components were powdered using a mill. The powder was weighed. These components were mixed with a ratio of $1: 1: 1: 1$, to 12 units of pure and natural honey (10). It was later incubated for at least 40 days at $37-38^{\circ} \mathrm{C}$, and then was packed in $100 \mathrm{~g}$ containers after the processing stage.

\subsection{Standardizing the $M D B$}

A sample of X (50 g) was suspended in $70 \%$ ethanol $(200 \mathrm{ml})$ and incubated for $72 \mathrm{~h}$ at $37{ }^{\circ} \mathrm{C}$ with gentle shaking (30). Then, the hydro-alcoholic extract was filtered through $250 \mu \mathrm{m}$ mesh and dried at $40 \mathrm{C}$ in a dry oven. The level of phenolic compounds in the extract was determined by the Folin-Ciocalteu method. A sample of the extract $(20 \mu \mathrm{L}$ of $10 \mathrm{mg} . \mathrm{mL})$ or garlic acid $(20 \mu \mathrm{L}$ of $0,50,100,150,250$, and $500 \mathrm{mg} . \mathrm{L})$ were added to Folin-Ciocalteu reagent $(100 \mu \mathrm{L})$. Next, $300 \mu \mathrm{L}$ sodium carbonate $(1 \mathrm{M})$ was added to the mixture and the volume was adjusted to $2 \mathrm{~mL}$ with deionized water. After 2 hours, the optical density was determined by a spectrometer at $765 \mathrm{~nm}$. The curve of gallic acid was constructed. One (I) level of phenolic compound in the extract was expressed as milligram of gallic acid equivalents (31). The solid residue of hydro alcoholic extract of MDB was 15.5 (31\%). The level of total phenolic compounds in the extract of MDB was $23 \mathrm{mg}$ garlic acid equivalent per gram of the extract. Considering the percentage of solid residue of the extract, each gram of MDB contains $7.13 \mathrm{mg}$ phenolic compounds equivalent to garlic acid (Figure 2). 


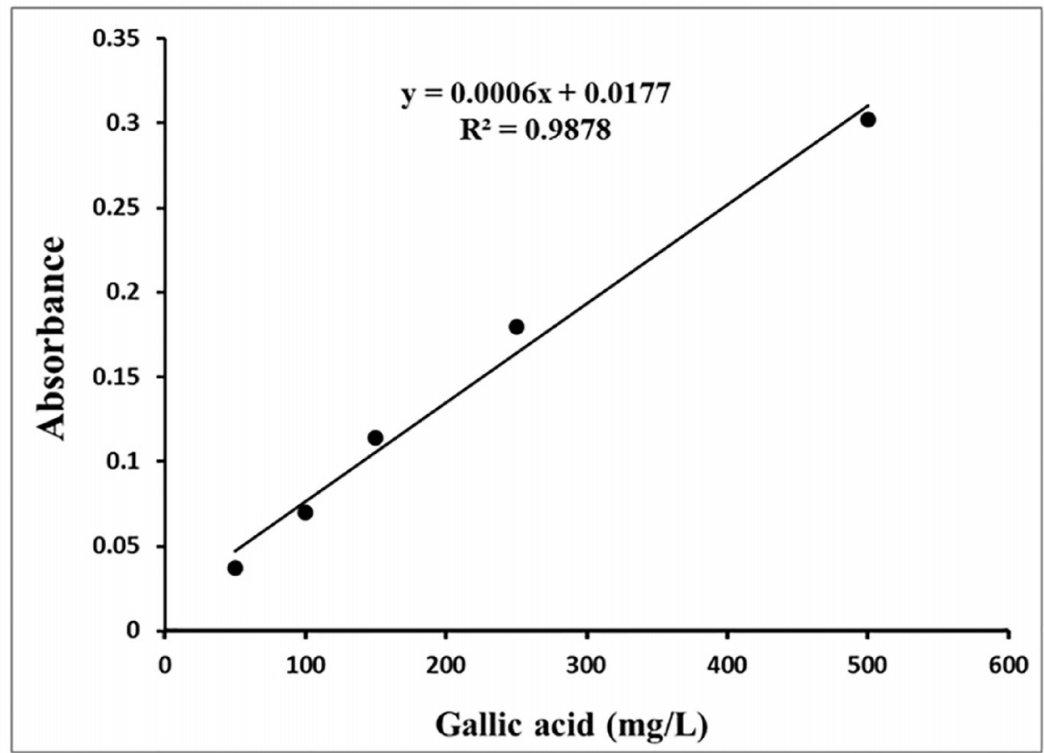

Figure 2. The average optical absorption of the extract (0.157)

\subsection{Outcomes}

The primary outcomes of our analyses were the rate reduction anthropometric index in the three intervention groups. Also, the secondary outcomes from the analyses were changes in body composition (FAT MASS\% and FREE FAT MASS \%) and laboratory parameters (CBC, FBS, HDL, LDL, Chol, TG, BUN, Cr, T3, T4, TSH, ALT, AST, Alkp, $\mathrm{Fe}, \mathrm{Zn})$ in the three intervention groups.

\subsection{Sample size}

Considering the lack of a similar study, merely on the basis of the experts' opinions, the impact of the classical method on overweightness was considered $40 \%$ and for the Persian method of medicine, was considered to be $50 \%$, the sample size was calculated using the formula for comparing ratios in two independent groups with $95 \%$ confidence and $80 \%$ power. The minimum sample size was considered 75 in each group. Six participants dropped out from intervention for personal or unascertained reasons and 69 of the women were analyzed.

\subsection{Randomization and blinding}

Our randomized, single blind clinical trial evaluated and compared the safety and efficacy of MDB as an herbal formulation and diet based on Persian medicine with classical medicine in treatment of 69 overweight women. To control bias in sampling with considering that the age variable is an interventional factor in the process of effective treatment, in addition to using the random allocation method, the population studied in three groups of 18 to 30 years old, 31 to 50 years and more than 50 years were classified. Then, by blocking method, three types of treatment interventions were performed in each age group. The subjects in each age group were assigned randomly to three groups: Group A, with Classical diet and orlistat, Group B, with Persian diet and herbal formulation, and Group C with classical diet and herbal formulation. Assignment management was based on the blocks during the sampling by the researcher. In collecting data for all patients, the same and calibrated instruments were used to measure height, weight and body composition, and the peripheral blood samples were obtained following 8 hours overnight fasting, and all measurements were performed at the laboratory of Mashhad University of Medical Sciences. In the data analysis stage, inferential analysis was performed based on the type of data distribution and in cases of abnormal distribution, non-parametric methods were used and in cases of normal distribution of data, T-test was used. The individuals who performed weight measurements at different stages did not know about the medication received. In the data analysis stage, the studied groups were identified as A, B and C. The person who measured the weight at different stages was not aware of the recommended drugs and diet type. A statistician, who was not involved in this study, produced separate random codes. After identifying each patient's code, the physicians introduced the patients to three different rooms in different places, which were specific to each group so that there was no relationship between patients in different groups. Sealed versions of these codes were stored for emergency identification. 


\subsection{Statistical methods}

Data was entered into the computer and analyzed using SPSS ver. 16. At first, the characteristics of each group were described using descriptive statistical methods, including central indicators, distribution and frequency distribution. For quantitative variables, their normalization was first measured using a K-S sample. To compare the quantitative variables before and after the study, paired-samples t-test for normal distribution of data in each group and nonparametric Wilcoxon test and ANOVA were used. Regression methods were used to control the intervention variables. P-values less than 0.05 were considered statistically significant.

\subsection{Research ethics}

This study was approved by the Ethics Committee of Mashhad University of Medical Sciences, with the reference number IR.MUMS.REC.1395.166 on June 20, 2016, and the enrollment of patients began on August 22, 2016 and continued up to December 20, 2016. This study was also registered in the Iranian Registry of Clinical Trials (irct.ir) with the ID (IRCT 2016041927477N1). We were given permission to conduct the thesis after the approval of the Ethics Committee, which is affiliated with the Deputy of Research of Mashhad University of Medical Sciences. Participation in the research was completely voluntary and all subjects were free to withdraw at any time during the course of the study. All the participants signed an informed consent form before enrolling in the study. We were committed to the confidentiality of all participants' information. The authors confirm that all ongoing tests related to this drug / intervention have been documented. Moreover, in this study, for ethical considerations, participants were informed about the purpose and nature of the study.

\section{Results}

In this clinical trial, 90 overweight women aged 18-60 were visited, 15 of whom were excluded. The remaining 75 women were screened for eligibility and with random allocation method, were categorized into three groups (18-30 years, 31-50 years, and $>50$ years) and then, by blocking method, three types of treatment interventions were performed in each age group. Six participants dropped out during the intervention for personal or unascertained reasons, and 69 of the women were analyzed. Table 1 presents the demographic characteristics of the participants. As specified in Table 1, the three treatment groups (A, B, C) showed no significant difference in demographic variables.

Table 1. Demographic characteristics of participants

\begin{tabular}{|l|l|l|l|l|l|}
\hline \multirow{2}{*}{ Variables } & Group A & Group B & Group C & \multirow{2}{*}{ p-value $^{1}$} \\
\cline { 3 - 5 } & $\mathrm{n}(\%) ;$ Mean \pm SD & $\mathrm{n}(\%) ;$ Mean \pm SD & $\mathrm{n}(\%) ;$ Mean \pm SD & & \multirow{2}{*}{0.786} \\
\hline \multirow{2}{*}{$\begin{array}{l}\text { Education } \\
\text { level }\end{array}$} & Under high school diploma & $10(43.5)$ & $8(34.8)$ & $10(43.5)$ & \\
\hline & University education & $13(56.5)$ & $15(65.2)$ & $13(56.5)$ & \\
\hline $\begin{array}{l}\text { Marital } \\
\text { status }\end{array}$ & Single & $3(13)$ & $5(21.7)$ & $8(34.8)$ & 0.213 \\
\hline Weight $(\mathrm{kg})$ & Married & $20(87)$ & $18(78.3)$ & $15(65.2)$ & \\
\hline Age $($ year) & $75.25 \pm 4.97$ & $75.45 \pm 6.24$ & $73.31 \pm 6.49$ & 0.408 \\
\hline BMI $\left(\mathrm{kg} / \mathrm{m}^{2}\right)$ & $38.39 \pm 11.94$ & $39.43 \pm 11.44$ & $39.00 \pm 11.28$ & 0.954 \\
\hline WC $(\mathrm{cm})$ & $29.44 \pm 0.88$ & $29.07 \pm 0.92$ & $28.52 \pm 1.00$ & 0.005 \\
\hline Height $(\mathrm{cm})$ & $94.65 \pm 5.05$ & $95.82 \pm 4.50$ & $95.26 \pm 4.43$ & 0.697 \\
\hline
\end{tabular}

1: Paired-samples t-test; BMO: Body Mass Index; WC: Waist circumference

Tables 2 and 3 present the statistics related to the outcomes. The results of paired-samples t-test to distinguish between treatment groups, showed anthropometric index and fat mass decrease, highly significant in all three intervention groups $(p<0.001)$ (Table 2$)$. Considering the non-normality of the free fat mass variable, the results of the Wilcoxon test in each treatment group showed that the mean free fat mass significantly differed in all three groups before and after the intervention $(\mathrm{p}<0.05)$. Group B led to a further decrease in BMI (Mean \pm SD: $1.61 \pm 1.03$, $\mathrm{p}<0.001$ ), weight (Mean \pm SD: 4.79 $\pm 2.26, \mathrm{p}<0.001$ ), waist circumference (Mean \pm SD: $4.25 \pm 0.59, \mathrm{p}<0.001$ ) and fat mass (Mean \pm SD: $3.24 \pm 2.70$ and $\mathrm{p}<0.001$ ), compared with the other two groups. Group A led to a further decrease in the free fat mass variable in the same group, than in other groups (Table 2). However, considering the effect of the treatment groups before and after intervention, there is no difference between groups A, B and C in terms of their treatment effectiveness. In addition, no side effects of the drugs were observed in either of the three treatment groups. The results of paired-samples t-test (before and after intervention) on the Chol and LDL variable showed that Group A had no significant effect before and after the intervention (P: 0.508), but groups B and C had significant effect before and after the intervention $(\mathrm{p}=0.029, \mathrm{p}=0.014)$ and Group B made the most changes (Table 
3). The results of paired-samples t-test on the TG variable also showed that the $\mathrm{B}$ and $\mathrm{C}$ groups did not have a significant effect, while Group B accounted for the most changes (SD: 59.34 \pm 69.92 , $\mathrm{p}=0.001$ ) (Table 3 ). The pairedsamples t-test results on the FBS variable show that Group A had no significant effect on this variable before and after intervention; but the results for groups $\mathrm{B}$ and $\mathrm{C}$ indicate the difference before and after the intervention and Group C produced the highest changes in $\mathrm{p}$-values $(\mathrm{p}<0.005)$ (Table 3$)$. The results of the ANOVA test indicate that there is no difference between the different treatment groups before and after the intervention, that is, the group effect is insignificant (Table 3). Also, the results of the ANOVA test show that there is a significant difference between the different treatment groups before and after the intervention. The results of the test of Bonferroni paired comparisons indicate that there is a difference between B and A groups, and this difference is also evident between the $\mathrm{C}$ and the $\mathrm{A}$ group, but there is no significant difference between the $\mathrm{C}$ and the $\mathrm{B}$ groups (Table 2). There was no significant change between the treatment groups in terms of the functioning of the kidneys or at the level of the liver enzymes before and after the intervention.

Table 2. Statistical test results of Anthropometric indexes and Body Composition at baseline and after 12 weeks of study

\begin{tabular}{|c|c|c|c|c|c|c|c|c|c|c|c|c|}
\hline \multirow{2}{*}{\multicolumn{2}{|c|}{ Statistical data }} & \multicolumn{3}{|c|}{ Baseline (Mean \pm SD) } & \multirow{2}{*}{\multicolumn{3}{|c|}{ After 12 weeks $($ Mean \pm SD) }} & \multirow{2}{*}{\multicolumn{3}{|c|}{$\begin{array}{l}\text { p-value (paired-samples } \\
\text { t-test) }\end{array}$}} & \multicolumn{2}{|c|}{$\begin{array}{l}\text { p-value } \\
\text { (ANOVA) }\end{array}$} \\
\hline & & & & & & & & & & & Baseline & \\
\hline \multicolumn{2}{|c|}{ Group } & A & B & $\mathrm{C}$ & A & B & $\bar{C}$ & A & B & $\mathrm{C}$ & & $\begin{array}{l}12 \\
\text { weeks }\end{array}$ \\
\hline \multirow[t]{3}{*}{$\mathrm{AI}$} & BMI $\left(\mathrm{kg} / \mathrm{m}^{2}\right)$ & $29.44 \pm 0.88$ & $29.07 \pm 0.92$ & $28.52 \pm 1.00$ & $28.09 \pm 1.12$ & $27.45 \pm 1.32$ & $27.08 \pm 1.11$ & $<0.001$ & $<0.001$ & $<0.001$ & 0.005 & 0.019 \\
\hline & Weight $(\mathrm{kg})$ & $75.25 \pm 4.97$ & $75.45 \pm 6.24$ & $73.31 \pm 6.49$ & $71.36 \pm 5.09$ & $70.63 \pm 5.65$ & $69.61 \pm 7.03$ & $<0.001$ & $<0.001$ & $<0.001$ & 0.408 & 0.613 \\
\hline & $\mathrm{WC}(\mathrm{cl}$ & $94.65 \pm$ & $95.75=$ & $95.26=$ & 91.34 & $91.5 \pm ?$ & $91.52 \pm 4.20$ & $<0.001$ & 0.001 & $<0.001$ & 0.869 & 0.996 \\
\hline \multirow[t]{2}{*}{$\mathrm{BC}$} & Fat mass (\%) & $30.22 \pm 3.73$ & $29.22 \pm 4.82$ & $26.38 \pm 4.71$ & $27.49 \pm 3.63$ & $25.97 \pm 4.85$ & $23.85 \pm 4.20$ & $<0.001$ & $<0.001$ & $<0.001$ & 0.013 & 0.019 \\
\hline & FFM (\%) & $49.68 \pm 8.82$ & $45.19 \pm 4.72$ & $46.43 \pm 3.24$ & $43.75 \pm 3.43$ & $43.80 \pm 4.94$ & $44.81 \pm 3.22$ & $<0.001$ & $<0.001$ & $<0.001$ & 0.603 & 0.647 \\
\hline
\end{tabular}

AI: Anthropometric Index; BMI: body mass index; WC: Waist circumference; FFM: Free Fat Mass\%; A: classical group (orlistat and conventional diet); B: Persian group (Persian diet and MDB); C: Mix group (conventional diet and MDB)

Table 3. Statistical test results of Laboratory Parameters at baseline and after 12 weeks of study

\begin{tabular}{|c|c|c|c|c|c|c|c|c|c|}
\hline \multirow{2}{*}{$\begin{array}{l}\text { Statistical data } \\
\text { Group }\end{array}$} & \multicolumn{3}{|c|}{ Baseline (Mean \pm SD) } & \multicolumn{3}{|c|}{ After 12 weeks (Mean \pm SD) } & \multicolumn{3}{|c|}{$\begin{array}{l}\text { p-value (paired- } \\
\text { samples t-test) }\end{array}$} \\
\hline & A & B & $\mathrm{C}$ & A & $\mathrm{B}$ & $\mathrm{C}$ & A & B & $\mathrm{C}$ \\
\hline FBS (mg/dL) & $91.71 \pm 9.61$ & $96.23 \pm 11.98$ & $94.55 \pm 13.78$ & $92.14 \pm 10.91$ & $89.27 \pm 12.82$ & $86.05 \pm 10.75$ & 0.834 & 0.004 & 0.005 \\
\hline CR (mg/dL) & $91.13 \pm 0.13$ & & $0.99 \pm 0.22$ & $0.89 \pm 0.13$ & $0.82 \pm 0.13$ & $0.93 \pm 0.22$ & 0.412 & & \\
\hline Urea $(\mathrm{mg} / \mathrm{dL})$ & $18.47 \pm 8.21$ & & & & $14.09 \pm 5.65$ & 5.91 & 0.196 & 0.070 & 018 \\
\hline TG $(\mathrm{mg} / \mathrm{dL})$ & 134.05 & 111.7 & 1.09 & $129.35 \pm 53.34$ & $105.04 \pm 35.88$ & $1 \pm 37.94$ & 0.618 & 0.140 & 01 \\
\hline Chol (mg/dL) & $176.57 \pm 39.12$ & $207.04 \pm 59.54$ & $205.36 \pm 41.82$ & $175.00 \pm 42.19$ & $171.04 \pm 25.18$ & $177.90 \pm 38.18$ & 0.834 & 0.001 & 0.0 \\
\hline $\mathrm{HDL}(\mathrm{mg} / \mathrm{dL})$ & $50.71 \pm 20.05$ & $51.22 \pm 7.85$ & $46.51 \pm 9.21$ & $46.50 \pm 14.06$ & $53.09 \pm 10.26$ & $47.22 \pm 8.06$ & 0.281 & 0.188 & 0.738 \\
\hline LDL (mg/dL) & $97.00 \pm 13.33$ & $127.86 \pm 25.77$ & $123.66 \pm 25.92$ & $101.38 \pm 29.64$ & $111.45 \pm 37.09$ & $112.18 \pm 24.36$ & 0.508 & 0.029 & 0.014 \\
\hline $\operatorname{AST}(\mathrm{u} / \mathrm{l})$ & & & & & & & 0.442 & & 220 \\
\hline & & & & & & & & & \\
\hline ALK & $164.89 \pm 42.91$ & $196.95 \pm 69.79$ & $181.47 \pm 32.45$ & $170.14 \pm 36.70$ & $185.90 \pm 52.27$ & $177.90 \pm 29.90$ & 0.362 & 0.152 & 0.580 \\
\hline WBC $(1000 / \mu \mathrm{L})$ & $6.58 \pm 0.89$ & $6.2 \pm 11.4$ & $6.31 \pm 1.42$ & $6.99 \pm 1.04$ & $6.14 \pm 1.48$ & $6.31 \pm 1.42$ & 0.378 & 0.826 & .189 \\
\hline $\mathrm{RBC}(1$ & $4.61=$ & 4.60 & & & & & 0.753 & 0.284 & 80 \\
\hline $\mathrm{Hb}(\mathrm{g} / \mathrm{dL})$ & $13.30 \pm 1.35$ & $12.87 \pm 1.36$ & $12.92 \pm 2.09$ & $13.14 \pm 1.25$ & $13.0 \pm 1.00$ & $13.39 \pm 0.98$ & 0.320 & 0.437 & 0.338 \\
\hline НCT $(\%)$ & & & & & & $40.06 \pm 0.62$ & 0.173 & 0.930 & 0.511 \\
\hline & & & & & & & 0.582 & 0.1 & 0.639 \\
\hline & & & & & & & 0.312 & 0.921 & \\
\hline PLT (1 & 0.51 & $258.10 \pm$ & 249.5 & 260. & $260.20 \pm 72.62$ & $257.04 \pm 50.99$ & 0.489 & 0.855 & 0.282 \\
\hline T3 (ng/dL) & $119.46 \pm 24.27$ & $142.54 \pm 91.99$ & $125.72 \pm 34.21$ & $119.69 \pm 20.54$ & $120.90 \pm 25.60$ & $127.75 \pm 25.01$ & 0.386 & 0.616 & 0.463 \\
\hline $\mathrm{T} 4(\mu \mathrm{g} / \mathrm{dL})$ & $05+4$ & $8.40 \pm 1.94$ & $9.21 \pm 2.44$ & $8.44 \pm 1$ & $8.13 \pm 1.00$ & $9.24 \pm 1$ & 0.105 & 0.594 & 0.936 \\
\hline TSH & $1.79 \pm 0.94$ & $1.62 \pm 0.93$ & $1.96 \pm 1.11$ & $1.65 \pm 0.71$ & $1.66 \pm 0.93$ & $2.33 \pm 1.20$ & 0.504 & 0.892 & 0.133 \\
\hline $\mathrm{Fe}$ & $92.69 \pm 25.36$ & $87.40 \pm 25.94$ & $90.90 \pm 29.72$ & $91.46 \pm 21.57$ & $87.70 \pm 30.48$ & $84.85 \pm 29.09$ & 0.810 & 0.963 & 0.303 \\
\hline $\mathrm{Zn}$ & $83.91 \pm 21.59$ & $79.57 \pm 22.23$ & $75.37 \pm 11.93$ & $83.91 \pm 19.32$ & $73.73 \pm 13.41$ & $79.45 \pm 16.70$ & 0.999 & 0.165 & 0.298 \\
\hline
\end{tabular}

Chol: cholesterol; LDL: low density lipoprotein cholesterol; HDL: high-density lipoprotein cholesterol; FBS: fasting insulin; AST: aspartate transaminase; ALT: alanine transaminase; ALP: alkaline phosphatase; WBC: white blood cells; RBC: red blood cells; MCV: mean corpuscular volume; MCHC: mean corpuscular hemoglobin concentration; CR: creatinine; T4: thyroxin; T3: triiodothyronine; TSH: thyroid stimulating hormone; Zn: Zinc 


\section{Discussion}

This is the first clinical trial evaluating and comparing the safety and efficacy of MDB as an herbal formulation and diet based on Persian Medicine with Classical Medicine in treatment of overweightness. According to Persian Medicine, regulating body weight in the normal range, plays an important role in the health of the organs of the body and their proper functioning, but obesity leads to dysfunction of the organs of the body, that the need for treatment is essential (32). The participants in this study were divided into three groups: A (classical diet and orlistat), B (Persian diet and MDB) and C (classical diet and MDB). Our results indicated a highly significant decrease in anthropometric index and body composition in all three groups $(\mathrm{p}<0.001)$, but difference in mean and standard deviation in Group B was higher than in the other two groups. The treatment success rate in this study was based on a reduction in BMI from 29.9 to less than 27, or an average weight loss of at least $2.5 \%$ and a maximum of $5 \%$ of the initial weight within 12 weeks. According to these goals, all three groups were successful in treating overweightness and during the 12-week treatment period, the mean weight loss in group B $(6.6 \%)$ was higher than Group A (5.16\%) and Group C (5.4\%) therefore Group B has been more successful in weight loss. This indicated that clinically, Persian Medicine can not only compete with Classical Medicine as a complementary medicine, but also with a greater force, can act as an alternative method in the treatment of obesity. When we measure the results of analysis variance between the groups, there is no significant difference; therefore, this indicated that there was no preference between the three intervention groups in the treatment of obesity. The results of paired-samples t-test (before and after intervention) on the serum lipid profile and fasting blood glucose, showed that Group A had no significant effect before and after the intervention $(\mathrm{p}=0.508)$, but groups $\mathrm{B}$ and $\mathrm{C}$ had significant effect before and after the intervention. This indicated that MDB and Persian diet decreases fasting blood glucose and lipid profiles significantly. By comparing groups A and B, it was found that in group B, due to synergistic effects of Persian diet and MDB, changes in anthropometric indexes, fat mass, lipid profile and fasting blood glucose were highly significant compared to Group A. Also, in the comparison of groups A and C, it was found that the reduction of anthropometric indexes, fat mass $\%$, lipid profile and fasting blood glucose in Group $\mathrm{C}$ was higher than that of Group $\mathrm{A}$; therefore, MDB has had more success in overweight treatment than orlistat. By comparing groups $\mathrm{B}$ and $\mathrm{C}$, it was found that Persian diet has been more successful than classical diet. The herbal formulation (MDB) consists of Nigella sativa, Carum copticum, Zataria multiflora and Mastic gum on a honey base (10). Various studies have shown that the components of MDB are effective in weight loss. A randomized clinical study evaluated the effect of natural honey on body weight and lipid profile in obese and normal weight subjects, and showed that honey has a low effect on weight loss and body mass index, but exceedingly improved lipid profile in obese people compared to a normal weight control group (33). Another animal study show that honey can be effective in weight loss and is effective in reducing appetite and intake of food, and also helps reduce blood triglyceride levels (34). In a single blind placebo-controlled study, 75 diagnosed primary hyperlipidemia patients were selected and were divided into three groups. Group-I was advised to take 10 grams of flaxseeds. Group-II was advised to take Ajwain (Carum copticum) and group-III was provided placebo capsules. It was concluded from the research that both flaxseeds and Carum copticum are effective in Primary Hyperlipidemia, if used for two months with specific concentrations (14). Other study investigates the effects of Zataria multiflora hydro alcoholic extract on some liver enzymes, triglyceride, cholesterol, HDL, LDL, albumin and total protein in rat. Sixty adult male Wistar rats weighing about 200 to $220 \mathrm{~g}$ were divided into six groups of ten. The results of this study showed that Zataria multiflora hydro alcoholic extract decreases lipid metabolism and lipid accumulation, and increases endogenous lipolysis and analyses various lipids in lipid tissues, consequently serum free triglycerides increase relative to dose (35). In an animal study that was conducted to evaluate the effect of Nigella Sativa extract on dietary intakes, body weight and some chemical parameters, it was concluded that the aqueous extract of Nigella sativa is effective in reducing weight and appetite, and decreases blood glucose and lipid profiles significantly (36). Two clinical trials demonstrated that the effect of N. sativa is effective in lowering weight and BMI significantly $(37,38)$. A randomized, placebo controlled clinical trial proved that Nigella sativa has a significant decrease in the concentration of total cholesterol (4.78\%), low density lipoprotein (7.6\%) and Triglyceride (16.65\%). This decrease was more significant for TG concentration (39). Other study showed that Nigella sativa reduced fasting blood sugar (40). A randomized, placebo-controlled study showed that Chios mastic gum (CMG) has a significant lowering effect on total cholesterol and glucose levels of healthy volunteers (19). Although various studies have shown that the components of MDB are effective in weight loss, there is little evidence that a natural compound with a mechanism of action, results in successful treatment of obesity (41). Therefore, a combination of different natural herbs with various mechanisms which may have synergistic effects, can be an effective approach to the treatment of obesity (42). It seems that MDB with the synergistic effects of its components could be more successful in treatment of obesity. In a study, Abdul Rahman et al indicated that the presence of various biologically active metabolites in plant extracts, especially polyphenols, has inhibitory effects on the activity of the pancreatic lipase enzyme which is considered as one of the most acceptable 
strategies for the treatment of obesity (43). According to various studies, Zataria multiflora (44), Nigella sativa (45), Carum copticum (46), Mastic gum (47) and Honey (48) have high levels of phenolic compounds that can be effective in the treatment of obesity. In my study, the standardization of the herbal formulation (MDB) showed that this drug contains a high percentage of flavonoids and other phenolic compounds. Persian Medicine has a holistic view in the prevention and treatment of obesity. It not only pays particular attention to the type of nutrients and their temperament, but also to the food calorie and the patient's digestion ability (29). In our study, from the comparison of groups $\mathrm{B}$ and $\mathrm{C}$, it was found that the reduction of anthropometric indexes, fat mass\%, lipid profile and fasting blood glucose in Group B was higher than that of Group C. Therefore, the role of the Persian diet was more prominent than the classic diet. Spices are rich in antioxidants, and types of spices are usually used for cooking, and increase metabolism and prevent obesity, diabetes and chronic inflammation and they activate PPAR $\alpha$ and PPAR $\gamma$ and increase the anti-inflammatory cytokines (49). In an animal study, Parvanlou et al. showed that the use of a diet containing hot and dry seeds reduces appetite and overweightness. The hot temperament groups compared to the cold temperament ones, showed a significant decrease in body weight gain on the 4th $(\mathrm{p}<0.01)$ and 7 th days $(\mathrm{p}<0.001)$ and a significant decrease in the total food intake after $24 \mathrm{~h}(\mathrm{p}<0.001)$ and during the 7 days $(\mathrm{p}<0.05)$ (50). There is a close relationship between the chemical compounds of herbs and their temperaments. Dr. Shams Ardekani et al. found that plants whose main components are phenolic compounds, have hot and dry temperament (51). So, by explaining the relationship between the temperament of food and its adaptation to principles of modern medicine, a new horizon in nutrition science will be created. Based on the sources of Persian Medicine, the main cause of obesity is cold and wet temperament and all plants and spices with a hot and dry temperament have good effect on the treatment of this disease; therefore, low caloric food with the addition of hot and dry spices is a suitable diet for overweightness (52). This study has some limitations, including the small sample size of 69 participants and the short-term duration of 12 weeks. Because this study was performed only in overweight adults, we could not determine the possible influence of Persian Medicine in obese patients. However, this study is of value in that this is the first randomized clinical trial to evaluate the efficacy and safety of the herbal formulation (MDB) and Persian diet for weight reduction with the classical diet and orlistat in overweight adults. To control bias in sampling with considering that the age variable is an interventional factor in the process of effective treatment, in addition to using the random allocation method, the population was studied in three groups of 18 to 30 years old and 31 to 50 years old and more than 50 years old were classified. Also, strict inclusion and exclusion criteria as well as the design of the study and intervention protocols are other strengths of this study.

\section{Conclusions}

In summary, the findings of this study showed Classical Medicine and Persian Medicine had the same levels of effectiveness in overweight treatment, but Persian Medicine brought a greater reduction in body weight, fat mass\%, lipid profile and fasting blood glucose than Classical Medicine during the study period. So, Persian Medicine as a complementary method, not only can clinically compete with Classical Medicine, but can even be proposed as an alternative method that can be effective in obesity as well as other physiological complications that increase oxidative stress. Future studies are strongly recommended to examine the mechanisms and biological processes of MDB and Persian diet that are effective in weight loss and metabolic syndrome.

\section{Acknowledgments:}

This study is a part of Ph.D. research. The authors have no conflicts of interest. The authors gratefully thank the Mashhad University of Medical Sciences for supporting the study.

\section{Funding:}

This paper is supported by a grant from the Research Council, Mashhad University of Medical Sciences, Mashhad, Iran.

\section{Trial registration:}

The trial was registered at the Iranian Registry of Clinical Trials (http://www.irct.ir) with the Irct ID: (IRCT 2016041927477N1).

\section{Conflict of Interest:}

There is no conflict of interest to be declared.

\section{Authors' contributions:}

All authors contributed to this project and article equally. All authors read and approved the final manuscript. 


\section{References:}

1) Ng M, Fleming T, Robinson M, Thomson B, Graetz N, Margono C, et al. Global, Regional and national prevalence of overweight and obesity in children and adults during 1980-2013: a systematic analysis for the Global Burden of Disease Study 2013. Lancet. 2014; 384: 766-81. doi: 10.1016/S0140-6736(14)604608. PMID: 24880830, PMCID: PMC4624264.

2) Gallagher M, Mahan L, Escott-Stump S, Raymond J. Krause's Food \& the Nutrition Care Process. 2012.

3) Segula D. Complications of obesity in adults: a short review of the literature. Malawi Med J. 2014; 26(1): 20-4. PMID: 24959321, PMCID: PMC4062780.

4) Fain JN. Release of inflammatory mediators by human adipose tissue is enhanced in obesity and primarily by the nonfat cells: a review. Mediators Inflamm. 2010; 2010: 513948. doi: 10.1155/2010/513948. PMID: 20508843, PMCID: PMC2874930.

5) Lijnen HR, Van Hul M, Hemmeryckx B. Caloric restriction improves coagulation and inflammation profile in obese mice. Thromb res. 2012; 129(1): 74-9. doi:10.1016/j.thromres.2011.05.023. PMID: 21689844.

6) Kang JG, Park CY. Anti-obesity drugs: a review about their effects and safety. Diabetes Metab J. 2012; 36(1): 13-25. doi: 10.4093/dmj.2012.36.1.13. PMID: 22363917, PMCID: PMC3283822.

7) Hasani-Ranjbar S, Nayebi N, Moradi L, Mehri A, Larijani B, Abdollahi M. The efficacy and safety of herbal medicines used in the treatment of hyperlipidemia; a systematic review. Current pharmaceutical design. 2010; 16(26): 2935-47. doi: 10.2174/138161210793176464.

8) Hasani-Ranjbar S, Nayebi N, Larijani B, Abdollahi M. A systematic review of the efficacy and safety of herbal medicines used in the treatment of obesity. World J Gastroenterol. 2009; 15(25): 3073. doi: 10.3748/wjg.15.3073. PMID: 19575486, PMCID: PMC2705729.

9) Ibn-e-Sina AH. Al-qanun fit-tib [The canon of medicine]. Beirut, Lebanon: Alaalami Beirut lib Press; 2005.

10) Aghili Shirazi MH. Qarabadin-e-Kabir [Great Pharmacopeia] (Lithograph in Persian). Tehran: Mahmoudi Press; 1970: 550-942.

11) Aghili Shirazi MH. Makhzan-al-advia (Persian). Tehran: Tehran University of Medical Sciences; 2009: 105-801.

12) Erejuwa OO, Sulaiman SA, Wahab AB. Honey: a novel antioxidant. Molecules. 2012; 17(4): 4400-23. doi: 10.3390/molecules 17044400 .

13) Hadi V, Kheirouri S, Alizadeh M, Hosseini H. Effects of Nigella sativa oil extract on inflammatory cytokine response and oxidative stress status in patients with rheumatoid arthritis: a randomized, doubleblind, placebo-controlled clinical trial. Avicenna J Phytomed. 2016; 6(1): 34-43. PMID: 27247920, PMCID: PMC4884216.

14) Jalbani D, Hakro DS, Murad D, Niaz DK, Qudoos DA, Moeen-Ud-Din H. Flaxseed and ajwain for primery hyperlipidemia. Drug Delivery and Therapeutics. 2016; 6(2): 37-9.

15) Triantafyllou A, Bikineyeva A, Dikalova A, Nazarewicz R, Lerakis S, Dikalov S. Anti-inflammatory activity of Chios mastic gum is associated with inhibition of TNF-alpha induced. Nutrition journal. 2011; 10(1): 64. 10. doi: 1186/1475-2891-10-64.

16) Sajed H, Sahebkar A, Iranshahi M. Zataria multiflora Boiss (Shirazi thyme) an ancient condiment with modern pharmaceutical uses. J Ethnopharmacol. 2013; 145(3): 686-98. doi: 10.1016/j.jep.2012.12.018. PMID: 23266333.

17) Samarghandian S, Azimini-Nezhad M, Farkhondeh T. The effects of Zataria multiflora on blood glucose, lipid profile and oxidative stress parameters in adult mice during exposure to bisphenol A. Cardiovasc Hematol Disord Drug Targets. 2016; 16(1): 41-6. PMID: 27349569.

18) Heshmati J, Namazi N, Memarzadeh MR, Taghizadeh M, Kolahdooz F. Nigella sativa oil affects glucose metabolism and lipid concentrations in patients with type 2 diabetes: A randomized, double-blind, placebocontrolled trial. Food Research International. 2015; 73(3): 379-85. doi: 10.1016/j.foodres.2015.01.030.

19) Kartalis A, Didagelos M, Georgiadis I, Benetos G, Smyrnioudis N, Marmaras H, et al. Effects of Chios mastic gum on cholesterol and glucose levels of healthy volunteers: A prospective, randomized, placebocontrolled, pilot study (Chios-mastiha). Eur J Prev Cardiol. 2016; 23(7): 722-9. doi: 10.1177/2047487315603186. PMID: 26311707.

20) Fernández-Sánchez A, Madrigal-Santillán E, Bautista M, Esquivel-Soto J, Morales-González A, EsquivelChirino C, et al. Inflammation, oxidative stress, and obesity. Int J Mol Sci. 2011; 12(5): 3117-32. doi: 10.3390/ijms12053117. PMID: 21686173, PMCID: PMC3116179. 
21) Jung UJ, Choi MS. Obesity and its metabolic complications: the role of adipokines and the relationship between obesity, inflammation, insulin resistance, dyslipidemia and nonalcoholic fatty liver disease. Int $\mathrm{J}$ Mol Sci. 2014; 15(4): 6184-223. doi: 10.3390/ijms15046184. PMID: 24733068, PMCID: PMC4013623.

22) Lee MS, Kim IH, Kim CT, Kim Y. Reduction of body weight by dietary garlic is associated with an increase in uncoupling protein mRNA expression and activation of AMP-activated protein kinase in dietinduced obese mice. J Nutr 2011; 141.11:1947-53. doi: 10.3945/ jn.111.146050. PMID: 21918057.

23) Whiting S, Derbyshire E, Tiwari B. Capsaicinoids and capsinoids. A potential role for weight management? A systematic review of the evidence. Appetite. 2012; 59: 341-8. doi: 10.1016/j.appet.2012.05.015. PMID: 22634197.

24) Akers JD, Estabrooks PA, Davy BM. Translational research: bridging the gap between long-term weight loss maintenance research and practice. Journal of the American Dietetic Association. 2010; 110(10): 1511 22. doi: 10.1016/j.jada.2010.07.005.

25) Wang WJ. Prevention and treatment of metabolic syndrome with integrated traditional Chinese and western medicine. Journal of Chinese Integrative Medicine. 2004; 2(5): 390-395. doi: 10.3736/jcim20040524.

26) Benjamin I, Griggs R, Wing E, Fitz JG, Andreoli T. Andreoli and Carpenter's Cecil Essentials of Medicine. 8th Edition. 2010.

27) Patwardhan B, Vaidya AD. Natural products drug discovery: accelerating the clinical candidate development using reverse pharmacology approaches. IJEB. 2010; 48(03): 220-7.

28) Chang SH, Stoll CR, Song J, Varela JE, Eagon CJ, Colditz GA. The effectiveness and risks of bariatric surgery: an updated systematic review and meta-analysis, 2003-2012. JAMA surg. 2014; 149(3): 275-87. doi: 10.1001/jamasurg.2013.3654. PMID: 24352617, PMCID: PMC3962512.

29) Azam Khan M. Exir Azam (Persian). Tehran: Institute of Meical History, Islamic Medicine and Complementary Medicine. 2008; 1: 575.

30) Ghorbani A, Hadjzadeh MR, Rajaei Z, Zendehbad SB. Effects of fenugreek seeds on adipogenesis and lipolysis in normal and diabetic rat. Pakistan Journal of Biological Sciences 2014; 17(4): 523-8. doi: 10.3923/pjbs.2014.523.528.

31) Hosseini A, Mollazadeh H, Amiri MS, Ghorbani A, Sadeghnia HR. Effects of a standardized extract of Rheum turkestanicum Janischew root on diabetic changes in the kidney, liver and heart of streptozotocininduced diabetic rats. Biomed Pharmacother. 2017; 86: 605-11. doi: 10.1016/j.biopha.2016.12.059.

32) Ahwazi AA. Kamel-al-Sanaeh (arabic) 1. 1st ed. Qom: Jalaoddin; 2008.

33) Mushtaq R, Mushtaq R, Khan ZT. Effects of natural honey on lipid profile and body weight in normal weight and obese adults: a randomized clinical trial. Pakistan Journal of Zoology. 2011; 43(1): 161-9.

34) Nemoseck TM, Carmody EG, Furchner-Evanson A, Gleason M, Li A, Potter H, Rezende LM, Lane KJ, Kern M. Honey promotes lower weight gain, adiposity, and triglycerides than sucrose in rats. Nutrition research. 2011; 31(1): 55-60. doi: 10.1016/j.nutres.2010.11.002.

35) Khoshvaghti A, Nazifi S, Derakhshaniyan S, Akbarpour B. The Effects of Zataria multiflora hydroalcoholic extract on some liver enzymes, cholesterol, triglyceride, HDL-Cholesterol, LDL Cholesterol, Albumin and Total Protein in Rat. J Basic Appl Sci. 2012; 8: 217-22. doi: 10.6000/19275129.2012.08.01.33.

36) Bano F, Wajeeh M, Baig N, Naz H, Akhtar N, Hajra N. Antiobesity, antihyperlipidemic and hypoglycemic effects of the aqueous extract of Nigella Sativa seeds (Kalongi). Pak J Biochem Mol Biol. 2009; 42(4): 136-40.

37) Qidwai W, Hamza HB, Qureshi R, Gilani A. Effectiveness, safety, and tolerability of powdered Nigella sativa (Kalonji) seed in capsules on serum lipid levels, blood sugar, blood pressure, and body weight in adults: Results of a randomized, double-blind controlled trial. J Altern Complement Med. 2009; 15: 63944. doi: 10.1089/acm.2008.0367.

38) Datau EA, Wardhana, Surachmanto EE, Pandelaki K, Langi JA, Fias. Efficacy of Nigella Sativa on serum free testosterone and metabolic disturbances in central obese male. Acta Med Indones. 2010; 42:130-4. PMID: 20724766.

39) Sabzghabaee AM, Dianatkhah M, Sarrafzadegan N, Asgary S, Ghannadi A. Clinical Evaluation of Nigella Sativa seeds for the treatment of hyperlipidemia: A randomized, placebo controlled clinical trial. Med Arch. 2012; 66: 198-200. PMID: 22822623.

40) Hoseini MS, Mirkarimi SA, Amini M, Mohtashami R, Kianbakht S, Fallah Hoseini H. Effects of Nigella sativa L. seed oil in type II diabetic Patients: A randomized, double-blind, placebo-controlled clinical trial. J Med Plants. 2013; 12: 93-9. 
41) Yun JW. Possible anti-obesity therapeutics from natur a review. Phytochemistry. 2010; 71: 1625-41. doi: 10.1016/j.phytochem.2010.07.011.

42) Rayalam S, Della-Fera MA, Baile CA. Phytochemicals and regulation of the adipocyte life cycle. J Nutr Biochem. 2008; 19: 717-26. doi: 10.1016/j.jnutbio.2 007.12.007.

43) Abdul Rahman H, Saari N, Abas F, Amin I. Anti-obesity and antioxidant activities of selected medicinal plants and phytochemical profiling of bioactive compounds. Food Properties. 2017; 20(11): 1-14. doi: 10.1080/10942912.2016.1247098.

44) Akhondzadeh Basti A, Misaghi A. Effects of Zataria multiflora Boiss. Essential oil and nisin on Bacillus cereus ATCC 11778. Food control. 2007; 18(9): 1043-9. doi: 10.1016/j.foodcont.2006.06.010.

45) D'Antuono LF, Moretti A, Lovato AF. Seed yield, yield components, oil content and essential oil content and composition of Nigella sativa L. and Nigella damascena L. Industrial crops and products. 2002; 15(1): 59-69. doi: 10.1016/S0926-6690(01)00096-6.

46) Boelens MH, Jimenez R. Chemical composition of the essential oils from the gum and from various parts of Pistacia lentiscus L. (mastic gum tree). J Flavor and fragrance. 1991; 6(4): 271-5. doi: $10.1002 / \mathrm{ffj} .2730060406$.

47) Goudarzi GH, Saharkhiz MJ, Sattari M, Zomorodian K. Antibacterial activity and chemical composition of Ajowan (Carum copticum Benth. \& Hook) essential oil. Agricultural Science and Technology. 2010; 13(2): 203-8.

48) Al-Mamary M, Al-Emery A, Al-Habor M. Antioxidant activities and total phenolic of different types of honey. Nutritional Research. 2002; 22(9): 1041-7. doi: 10.1016/S0271-5317(02)00406-2.

49) Jungbauer A, Medjakovic S. Anti-inflammatory properties of culinary herbs and spices that ameliorate the effects of metabolic syndrome. Maturitas. 2012; 71(3): 227-39. doi: 10.1016/j.maturitas.2011.12.009. doi: 10.1016/j.maturitas.2011.12.009.

50) Parvinroo S, Zahediasl S, Sabetkasaei M, Kamalinejad M, Naghibi F. The effects of selected hot and cold temperament herbs based on Iranian traditional medicine on some metabolic parameters in normal rats. Iran J Pharm Res. 2014; 13.Suppl: 177-84. PMID: 24711844, PMCID: PMC3977068.

51) Ardekani MR, Rahimi R, Javadi B, Abdi L, Khanavi M. Relationship between temperaments of medicinal plants and their major chemical compounds. J Tradit Chin Med. 2011; 31(1): 27-31. doi: 10.1016/S02546272(11)60006-X. PMID: 21563502.

52) Arzani MA. Teb-e-Akbari [Akbari's Medicine]. Ehya Teb e Tabiee. Tehran: Jalaleddin Press; 2008. 